\title{
Non-metallic inclusions interpretation technique for factory expertise of metal product defects
}

\author{
A. A. Kazakov, Dr. Eng., Prof., Head of "Metallurgical Examination” Lab.1, e-mail: kazakov@thixomet.ru \\ V. A. Murysev, Chief Specialist of the Engineering and Technology Center ${ }^{2}$ \\ D. V. Kiselev, Technical Director, "Metallurgical Examination" Lab. ${ }^{1}$
}

1 "Thixomet” JSC, St. Petersburg, Russia

2JSC Vyksa Steel Works, Vyksa, Russia

The technique of processing the results of factory experts' reports has been developed to interpret the origin of nonmetallic inclusions (NMIs) detected in the defects of a welded pipe joints made of J55 API 5L (22GYu) steel. Thermodynamic simulation was performed to assess the possibility of the indigenous origin of these inclusions. The results of such a simulation were summarized using radar diagrams of four clusters uniting NMIs with similar composition of deoxidation and modification products. More than 130 compositions of actual inclusions detected on dozens of welded joints samples were processed and combined into four clusters in the same way. After a comparative analysis of these two types of radar diagrams, the origin of all clusters of actual inclusions was established, three of which are predominantly exogenous inclusions and the fourth is predominantly indigenous. None of the clusters contains only indigenous inclusions or only exogenous ones. The main source of inclusions in the discontinuities of welded joints is inclusions conglomerates, sorbed on the refractories surface, contacted with molten steel during its ladle treatment and pouring. These sintered conglomerates of indigenous and exogenous inclusions, that form three clusters of four ones, were out washed by the flow of steel melt into the crystallizer during steel pouring. The reasons for the formation of the fourth cluster are related to "cold welding". The technique is implemented as a plug-in of Thixomet Pro image analysis system and allows to automate the process of metallographic conclusions generation in factory practice, as well as to accumulate all information in a database for its subsequent processing and analysis.

Key words: metal products defects, non-metallic inclusions, exogenous, indigenous, clustering, thermodynamics, origin, automation.

DOI: $10.17580 /$ cisisr.2021.02.08

\section{Introduction}

For various reasons defects are formed as discontinuities, which are identified by methods of nondestructive testing used by industry to evaluate the properties of materials in the conditions of mass industrial production. To determine the origin of their formation, investigations using light optical and scanning electron microscopy methods have to be made. The results of these studies are used to improve the technology at all stages of industrial production of metal products from the steelmaking process to the finished product [1-3].

Frequently, non-metallic inclusions (NMIs), including those inherited from the continuous cast billet, are the cause of the formation of discontinuities [1-2]. These inclusions can be exogenous, indigenous or mixed in origin. As a rule, the conclusion about the origin of inclusions is performed by a researcher of the testing laboratory, relying on his personal experience; therefore, all formulations of such reports reflect the individual approach of each engineer and are not universal. Such reports can only be processed manually, so they often go unclaimed, since they are not suitable for automated processing, for example, for finding patterns of defect formation and the ways to eliminate them.

An objective judgment about the belonging of inclusions to the indigenous products of deoxidation and modification can be given on the basis of thermodynamic simulation of their composition [4-6]. Specialized commercial software
Thermo-Calc Software, FactSage, etc. [7-9] have been used in universities, research institutes and industrial enterprises for decades. Such software allows to find the equilibrium composition of non-metallic inclusions with the known steel composition, but they do not solve the inverse problem, which arises in the metallurgical examination: from the steel of what composition did the inclusions found in the vicinity of the defect form? Finally, such software applications are not designed to process the databases of compositions of actual inclusions found in the study of defects and accumulated over many years, which is necessary to establish general patterns of their formation and to develop methods to control them.

The aim of the present work is to develop a method of processing the compositions of inclusions found in the vicinity of metal products defects, as well as compositions of indigenous non-metallic inclusions, calculated by thermodynamic modeling methods, the comparative results of which in the factory practice can be used to explain the origin of NMIs during expert examination.

Materials and research methods

Metal defects in welded joints obtained by high-frequency welding of pipes made from rolled coils of J55 API $5 \mathrm{~L}(22 \mathrm{GYu})$ steel with the average chemical composition given in Table 1 were investigated. Hereinafter in the text, in the tables and in the figures the concentrations of elements are given in weight 
percent. The defects were detected by ultrasonic inspection of the weld and examined using Axio Observer D1m inverted microscope equipped with the Thixomet Pro image analysis system, after appropriate grinding and polishing on Buehler equipment and subsequent etching with Nital.

The chemical composition of non-metallic inclusions detected without etching on the cross sections taken in the vicinity of defects in pipe welds was investigated by SEM-EDS analysis on an microscope JSM-6380LA. In total more than 130 inclusions detected in 73 welded joints were investigated.

For thermodynamic modeling the commercial software FactSage 8.0 complete with the FSstel and FToxid databases [8] was used.

\section{Results and discussion \\ Thermodynamic modeling of deoxidation processes of J55 API 5L (22GYu) steel}

The composition of steel, given in Table 1, was taken as a basis for thermodynamic modeling. The influence of calcium and magnesium on the composition of indigenous inclusions was studied. The calcium content depends on the depth of preliminary deoxidation, steel temperature, the degree of its assimilation by the melt and other factors, and it changes from heat to heat. Magnesium is not specifically added, but strong deoxidizers such as aluminum and calcium can reduce it from $\mathrm{MgO}$-containing refractories or slag during ladle treatment [10-11]. In addition, magnesium as an impurity element is contained in some deoxidants. Magnesium from the above-mentioned sources will participate in the formation of NMIs in the molten steel. The oxygen content depends on the preliminary deoxidation of steel before its calcium treatment with calcium silicon alloy. Taking into account its known concentration in actual production, we set $[\mathrm{O}]=0,002 \%$. The content of silicon, aluminum and sulfur before the addition of calcium is about the same in all the studied steels, so their average values were taken from Table 1 .

Suppose that deoxidation products in composition of conglomerates found in the weld discontinuities are the primary inclusions formed after calcium treatment at $1550{ }^{\circ} \mathrm{C}$. To calculate the composition of such indigenous inclusions formed in the liquid steel, the thermodynamic modeling of deoxidation and modification processes were carried on.

Fig. 1 shows the amount and composition of NMIs formed in J55 API 5L (22GYu) steel with average composition (Table 1) versus the calcium content when its varying from 0.0005 to $0.01 \%$ in steps of $0.0005 \%$ with fixed magnesium content $[\mathrm{Mg}]=0.0005 \%$ (Fig. $1 a),[\mathrm{Mg}]=0.002 \%$ (Fig. $1 b)$ and $[\mathrm{Mg}]=0.006 \%$ (Fig. $1 c$ ).

The concentrations of these elements are chosen so as to obtain a different combination of compositions of the steel solution when dissolving the calcium silicon alloy wire in it, when these elements change in a wide range, significantly different from the residual contents in the finished metal.

Calcium changes due to its extremally low solubility in the liquid steel and the nonuniform distribution around the injection point

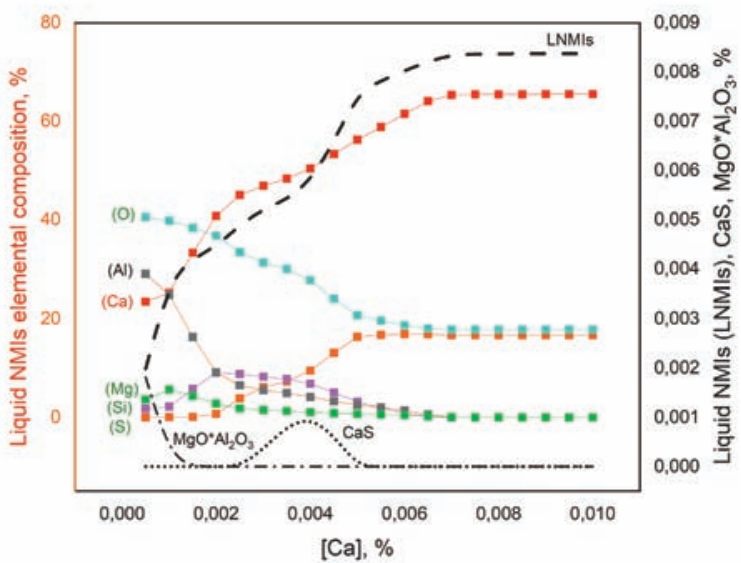

a) $[\mathrm{Mg}]=0,0005 \%$

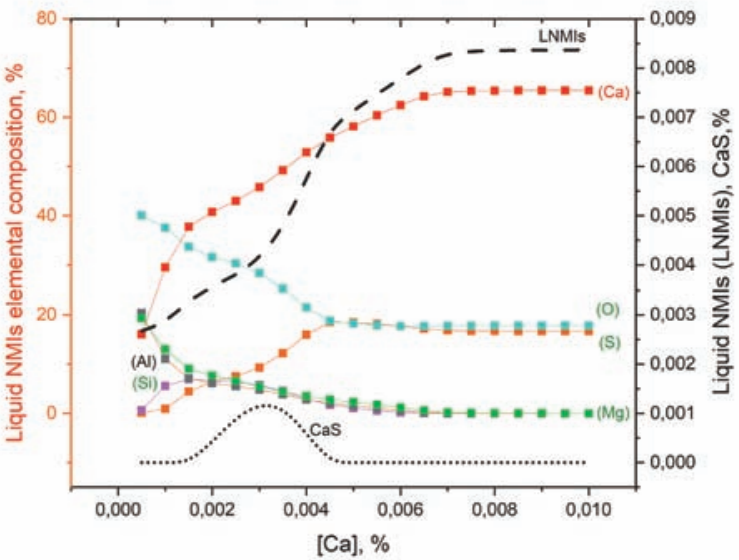

b) $[\mathrm{Mg}]=0,002 \%$

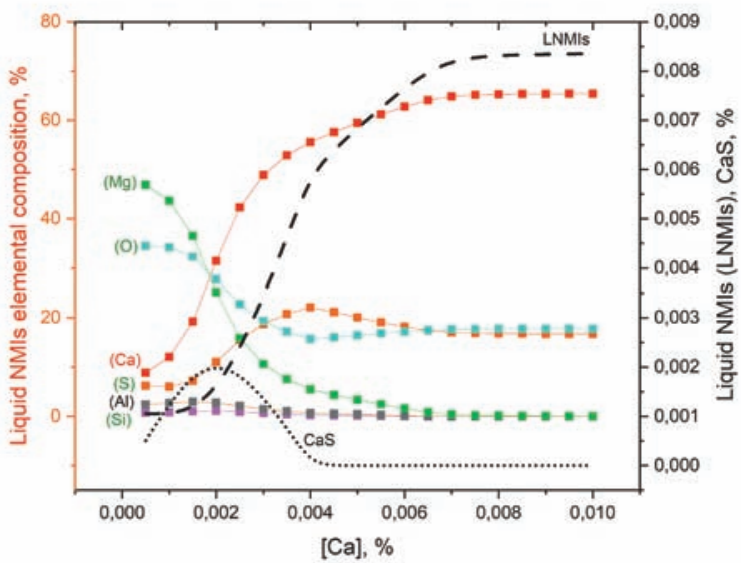

c) $[\mathrm{Mg}]=0,006 \%$

Fig. 1. Effect of calcium and magnesium on the amount and composition of indigenous NMIs in liquid steel at $1550^{\circ} \mathrm{C}$
Table 1. Average composition of the investigated J55 API 5L (22GYu) steel, \%

\begin{tabular}{|c|c|c|c|c|c|c|c|}
\hline $\mathrm{C}$ & $\mathrm{Si}$ & $\mathrm{Mn}$ & $\mathrm{B}$ & $\mathrm{P}$ & $\mathrm{S}$ & $\mathrm{Al}$ & $\mathrm{N}$ \\
\hline 0.227 & 0.236 & 1.066 & 0.0001 & 0.0071 & 0.0014 & 0.0165 & 0.0087 \\
\hline $\mathrm{Cr}$ & $\mathrm{Ni}$ & $\mathrm{Cu}$ & $\mathrm{Ti}$ & $\mathrm{Ca}$ & $\mathrm{Mo}$ & $\mathrm{V}$ & $\mathrm{Nb}$ \\
\hline 0.177 & 0.076 & 0.152 & 0.0013 & 0.0013 & 0.0088 & 0.0019 & 0.0032 \\
\hline
\end{tabular}




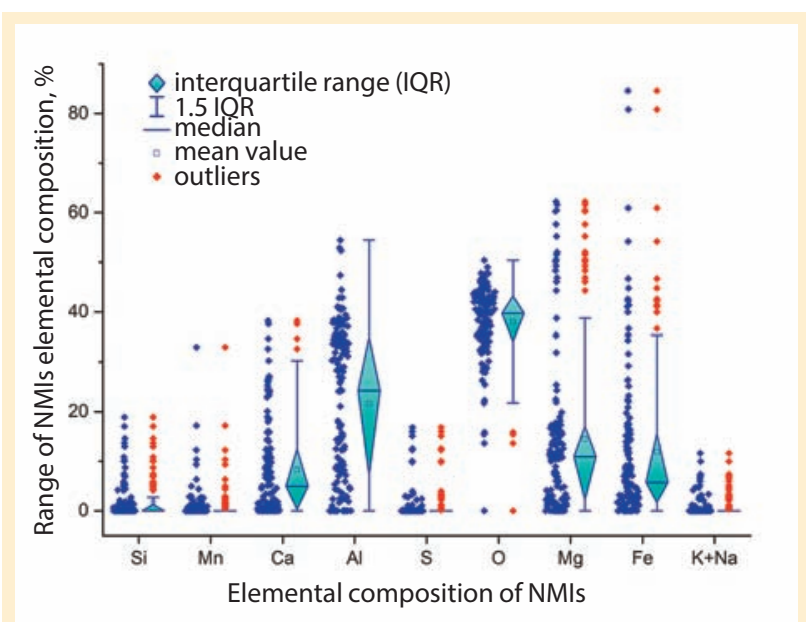

Fig. 2. Compositions of actual non-metallic inclusions detected in discontinuities of welded joints and their descriptive statistics

of the wire, while the concentration of magnesium changes depending on the depth of its reduction from the slag or refractory [10-11].

At all studied magnesium contents, the greatest change in the composition of deoxidation and modification products was found when the calcium content was increased from $0.0005 \%$ to $0.004-0.005 \%$ (Fig. 1). In this range, the fractions of $\mathrm{Al}_{2} \mathrm{O}_{3}$ and $\mathrm{MgO}$ in the composition of liquid non-metallic inclusions (LNMIs) decrease, and the fraction of $\mathrm{SiO}_{2}$ slightly increases, reaching maximum values at $[\mathrm{Ca}]=0.0015-0.0020 \%$. These maximum values are the greater the less magnesium in the liquid steel. At $[\mathrm{Ca}] \geq 0.006 \% \mathrm{SiO}_{2}$ is not formed in the composition of liquid inclusions.

Spinel $\mathrm{MgO}-\mathrm{Al}_{2} \mathrm{O}_{3}$ is formed in a narrow concentration range only at $[\mathrm{Mg}]<0.0005 \%$ and $[\mathrm{Ca}]<0.0015 \%$ in steel (Fig. 1a). CaS, as an independent compound, forms in the range of $0.0005 \%<[\mathrm{Ca}]<0.004 \%, 0.0015 \%<[\mathrm{Ca}]<0.0046 \%$ and $0.0025 \%<[\mathrm{Ca}]<0.005 \%$ at $[\mathrm{Mg}]=0.006 \%, 0.002 \%$ and $0.0005 \%$ respectively (Fig. 1). If $[\mathrm{Ca}]>0.005 \%$, only liquid inclusions on the basis of CaO-CaS are formed at any content of magnesium in the steel.

Additionally, at the same variation of calcium content the compositions of inclusions equilibrium with $[\mathrm{Mg}]=0.001 \%$ and $0.004 \%$ were calculated. A total of one hundred compositions of indigenous inclusions formed at $1550{ }^{\circ} \mathrm{C}$ were calculated at different combinations of calcium and magnesium in the liquid steel. The compositions of these LNMIs were estimated by the concentrations of their constituent elements to further compare them conveniently with the composition of actual inclusions found in the vicinity of defects and obtained by SEM-EDS analysis.

\section{The results of the study of NMIs compositions, detected in the vicinity of defects of a welded pipe joints made of J55 API 5L (22GYu) steel}

Fig. 2 shows elemental constituents of NMIs detected inside discontinuities of welded joints and descriptive statistics for these inclusions, from which the range of element concentrations changes detected in NMIs during the examination of metal products defects is clear.

Outliers marked with red dots on the descriptive statistics can be associated with "non-systematic" or accidentally introduced into the melt from the outside exogenous inclusions. Thus, iron outliers in the NMIs composition would add arguments in favor of their exogenous origin associated, for example, with secondary oxidation during pouring or "cold welding". If the small iron content in fine inclusions can be "written off as background" of the metal matrix, the $(\mathrm{Fe})>5-7 \%$ content cannot be attributed to a hardware error of composition measurement. The same remark applies to the content of manganese $\mathrm{Mn}>2 \%$. The presence of alkaline earth metals in inclusions indicates their interaction with the slag in the tundish or in the crystallizer, and the silicon outliers in combination with alkaline earth metals lead to the final conclusion about this interaction. Magnesium outliers are indicative of periclase or magnesite particles and aluminum outliers are indicative of corundum. All these inclusions have to be associated with the refractory materials contacted with steel melt during ladle treatment and pouring.

The above outlier analysis is useful for detecting individual elements in the inclusions, which can serve as a sign of their exogenous origin, but neither this analysis, nor the analysis of other descriptive statistics solves the problem of complete identification of NMIs. Moreover, when regularly penetrating into the steel melt, exogenous inclusions can also turn out to be "systematic" and then they fall within the interquartile range [12].

To solve the problem of reasonable separation of indigenous and exogenous inclusions, we should analyze not the individual elements in their composition, but their combinations with each other and in comparison with the compositions of indigenous inclusions known from thermodynamic simulation. For such a systematic analysis of the different compositions of indigenous inclusions found by simulations and the compositions of NMIs found in the vicinity of defects, we used clustering of these two types of inclusions and subsequent pairwise joint analysis of the found clusters using radar diagrams.

\section{Cluster analysis and interpretation of non-metallic inclusions}

To summarize the chemical compositions of the nonmetallic inclusions found in the vicinity of the defects, on the one hand, and the indigenous inclusions found by thermodynamic simulation, on the other hand, we calculated clusters combining similar compositions in each of these two groups of NMIs [13].

The number and composition of individual clusters were found by the k-means method [14]. The number of clusters was chosen by analyzing the behavior of "distortions", which were calculated as the sum of the squares of the Euclidean distances between the points corresponding to the composition of individual NMIs and the center of the cluster to which these NMIs belong (distortion 1) and as the mean square of the distances from the center of one 
cluster to the centers of other clusters (distortion 2). As the number of clusters increases, distortion 1 decreases and distortion 2 increases (Fig. 3).

The optimal number of clusters was chosen based on the analysis of these two distortions versus the number of clusters: the separation of inclusions into groups was completed when the change in these curves stabilized and did not lead to the appearance of clusters with markedly different compositions. Based on these considerations, for inclusions found in the vicinity of defects and for indigenous NMIs found by thermodynamic simulation, the number of clusters was chosen to four for each type of inclusions (Fig. 3).

The compositions of clusters - products of deoxidation and modification in J55 API 5L (22GYu) steel are given in Table 2. As follows from Table 2, three clusters out of four (No. 2, No. 3 and No. 4) contain compounds of the Ca-O-S system.

More over the cluster No. 4 consists almost only of $\mathrm{CaO}-\mathrm{CaS}$ with approximately equal concentrations of oxygen and sulfur. Indeed, as follows from Fig. 1, at $1550{ }^{\circ} \mathrm{C}$ and $[\mathrm{Ca}] \geq 0.005 \%$ almost only $\mathrm{CaO}-\mathrm{CaS}$ inclusions are formed.

Using the same clustering technique, all compositions of inclusions found in defects of welded joints were processed (Table 3).

Note that the first three clusters do not contain sulfur, or its content does not exceed $0.23 \%$. Only the fourth cluster contains $3.41 \%$ of sulfur (Table 3), which is 2-6 times less than the concentrations that should be in any of the clusters of indigenous inclusions-products of deoxidation and modification (Table 2). On the basis of this analysis, we can already state that the contribution of indigenous inclusions to the formation of defects in welded joints is insignificant.

For illustrative purposes, we use radar diagrams to compare the compositions of the clusters of actual inclusions found in defects of welded joints with the compositions of indigenous NMIs clusters (Fig. $4 \boldsymbol{a}$ to Fig. 7a). The compositions of all studied actual inclusions for each cluster and their descriptive statistics are given in Fig. $\mathbf{4 b}-$ Fig. $\mathbf{7 b}$.

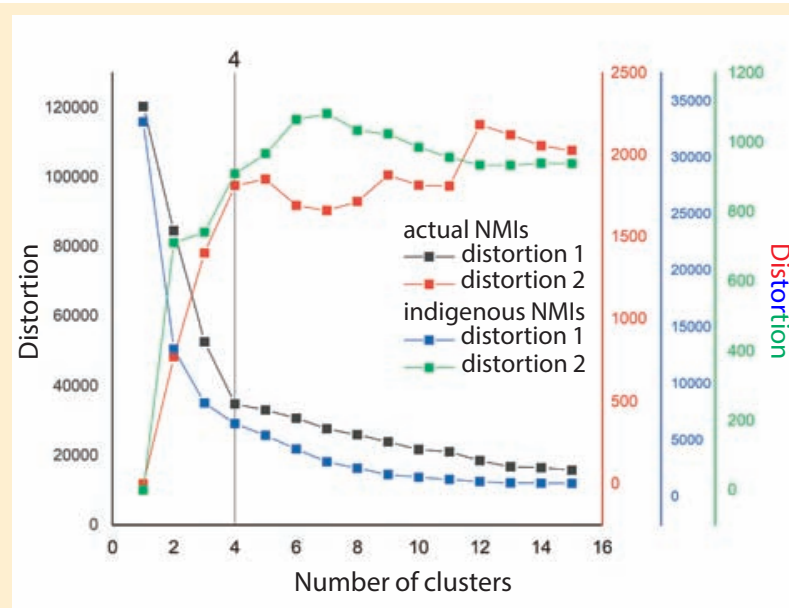

Fig. 3. Distortions to choose the optimal number of clusters of actual and indigenous NMIs in J55 API 5L (22GYu) steel
As follows from Table 3 and Fig. 4, more than $50 \%$ of all inclusions found in the vicinity of the studied defects belong to cluster No. 1 and are pure magnesia spinel or $\mathrm{Al}_{2} \mathrm{O}_{3}-\mathrm{MgO}$ with a small content of calcium aluminates. These NMIs are erosion products, which can be pure refractory particles or the same particles but impregnated with deoxidation and modification products. The presence of alkaline earth metals indicates the interaction of these NMIs with the slag in the tundish or in the crystallizer. As a rule, these inclusions are located on the welded edge near the fusion line in a discontinuity extended along the lines of metal flow.

As follows from Fig. 5, cluster No. 2 is practically pure magnesium oxide $\mathrm{MgO}$, of which refractories (periclase or magnesite) are made, less often it is impregnated with small amounts of liquid calcium aluminates - products of deoxidation and modification of steel. Along with these inclusions, NMIs from cluster No. 4 (calcium aluminates with magnesia spinel) occur. A discontinuity with such inclusions is located near the fusion line along the metal flow lines, usually without reaching the external surface.

As follows from Fig. 6, cluster No. 3 is almost pure iron oxide with admixtures of calcium aluminates and/or magnesia spinel.

The defects are mainly located on the fusion line, related to "cold welding" and are formed due to the low temperature of the welded edges during pipe upsetting.

As follows from Fig. 7, exo-indigenous inclusions consisting mainly of deoxidation and modification products (calcium

\begin{tabular}{|c|c|c|c|c|}
\hline & 1 & 2 & 3 & 4 \\
\hline Clusters & O-Ca-Al-Mg & $\begin{array}{l}\mathrm{Ca}-\mathrm{O}-\mathrm{Mg}- \\
\mathrm{Al}-\mathrm{S}-\mathrm{Si}\end{array}$ & Ca-S-O-Mg & Ca-O-S \\
\hline Elements & \multicolumn{4}{|c|}{ Elemental composition of NMIs clusters, \% } \\
\hline $\mathrm{Ca}$ & 24.42 & 36.75 & 49.09 & 63.61 \\
\hline 0 & 39.57 & 31.97 & 18.79 & 17.82 \\
\hline $\mathrm{S}$ & 0.07 & 6.65 & 20.53 & 17.27 \\
\hline $\mathrm{Mg}$ & 8.78 & 10.96 & 6.11 & 0.67 \\
\hline $\mathrm{Al}$ & 22.27 & 6.69 & 2.48 & 0.35 \\
\hline $\mathrm{Si}$ & 2.33 & 6.07 & 2.66 & 0.24 \\
\hline
\end{tabular}

\begin{tabular}{|c|c|c|c|c|}
\hline \multirow[b]{2}{*}{ Clusters } & 1 & 2 & 3 & 4 \\
\hline & O-Al-Mg-Fe & $\mathrm{Mg}-\mathrm{O}-\mathrm{Fe}$ & $\mathrm{Fe}-\mathrm{O}-\mathrm{Al}-\mathrm{Mg}$ & $\begin{array}{c}\text { O-Ca-Al- } \\
\text { Fe-Mg }\end{array}$ \\
\hline $\begin{array}{l}\text { Fraction in } \\
\text { defects, \% }\end{array}$ & 50.38 & 12.98 & 11.45 & 25.19 \\
\hline \multicolumn{5}{|c|}{ Elemental composition of NMls clusters, \% } \\
\hline $\mathrm{Ca}$ & 4.86 & 1.48 & 4.17 & 20.43 \\
\hline 0 & 41.74 & 36.62 & 25.42 & 36.90 \\
\hline S & 0.00 & 0.12 & 0.23 & 3.41 \\
\hline $\mathrm{Mg}$ & 11.17 & 51.02 & 7.02 & 5.58 \\
\hline $\mathrm{Al}$ & 35.21 & 1.40 & 9.69 & 10.53 \\
\hline $\mathrm{Si}$ & 0.60 & 0.03 & 1.78 & 4.54 \\
\hline $\mathrm{Fe}$ & 5.34 & 9.14 & 47.82 & 10.02 \\
\hline $\mathrm{K}+\mathrm{Na}$ & 0.54 & 0.16 & 0.65 & 1.51 \\
\hline
\end{tabular}




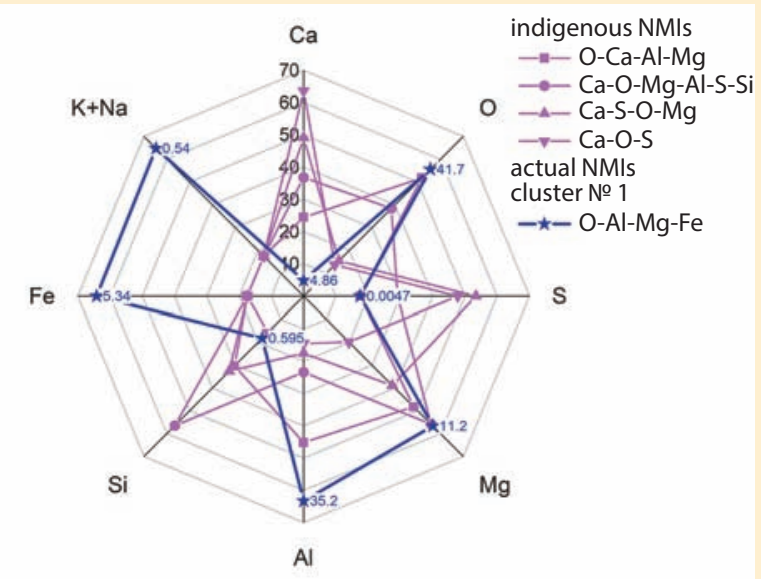

a)

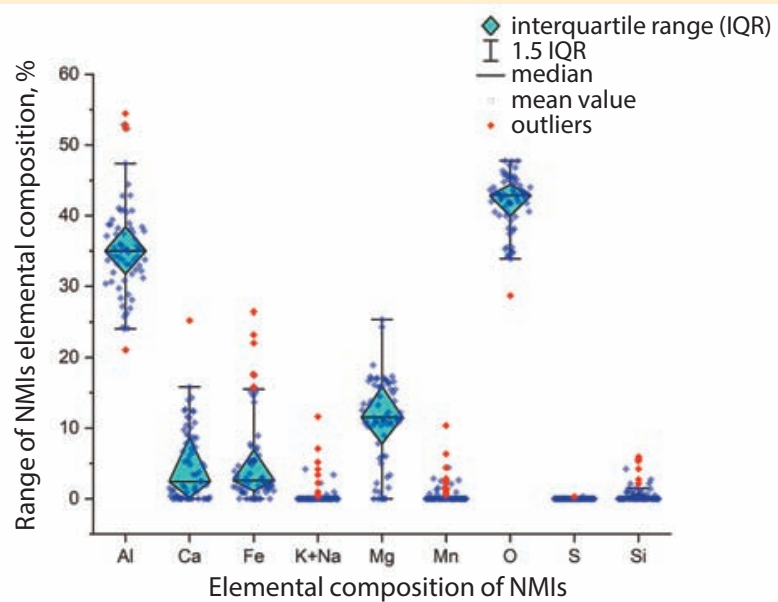

b)

Fig. 4. Compositions of actual inclusions cluster No. 1 and indigenous NMIs in steel $(a)$; compositions of all studied actual inclusions of cluster No. 1 and their descriptive statistics (b)

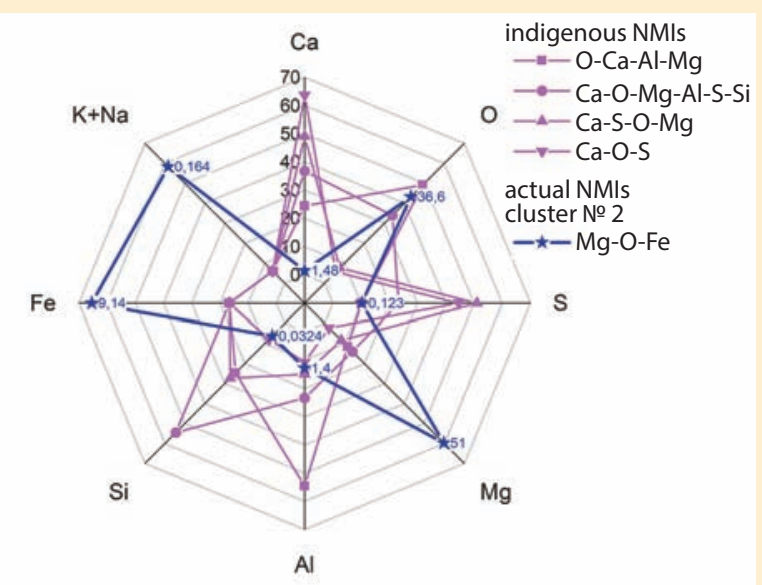

a)

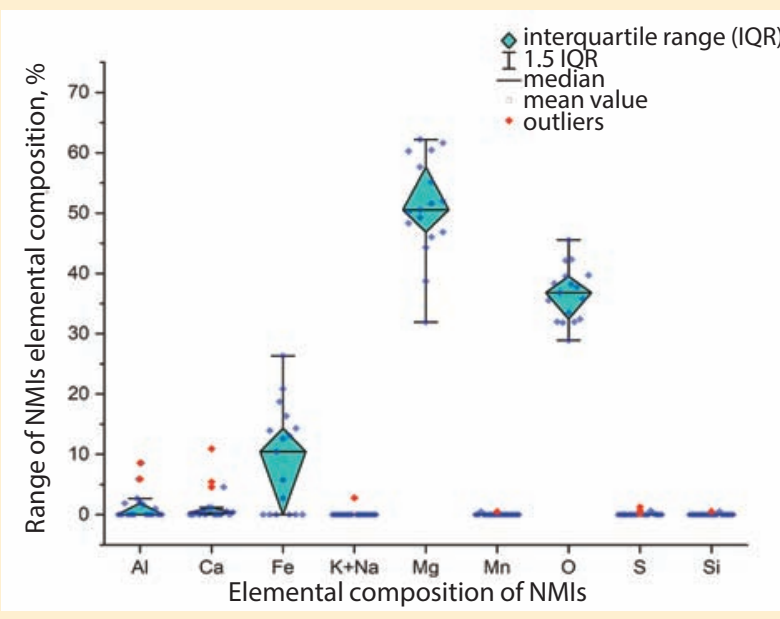

b)

Fig. 5. Compositions of actual inclusions cluster No. 2 and indigenous NMIs in steel (a); compositions of all studied actual inclusions of cluster No. 2 and their descriptive statistics (b)

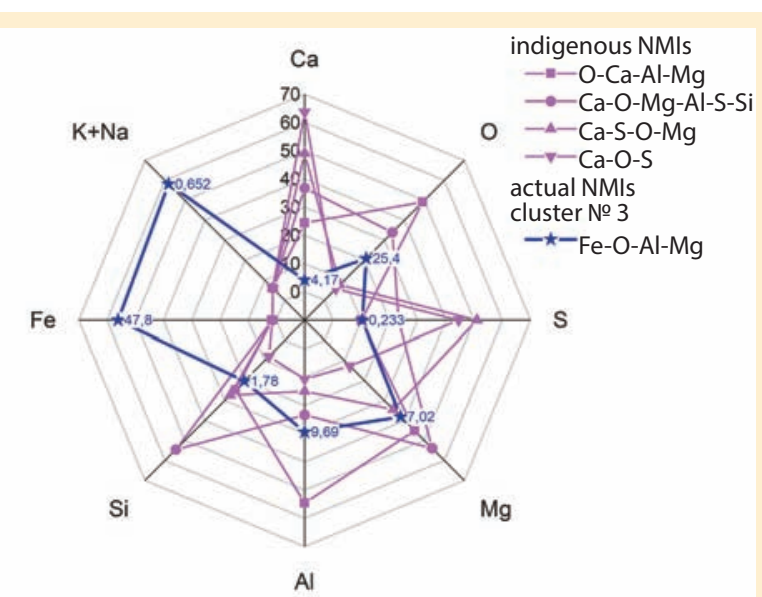

a)

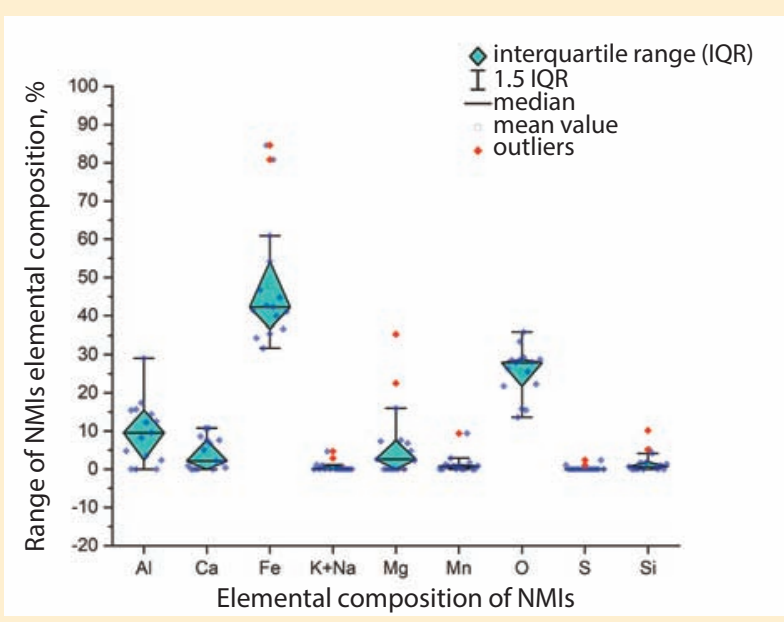

b)

Fig. 6. Compositions of actual inclusions cluster No. 3 and indigenous NMIs in steel (a); compositions of all studied actual inclusions of cluster No. 3 and their descriptive statistics $(b)$ 


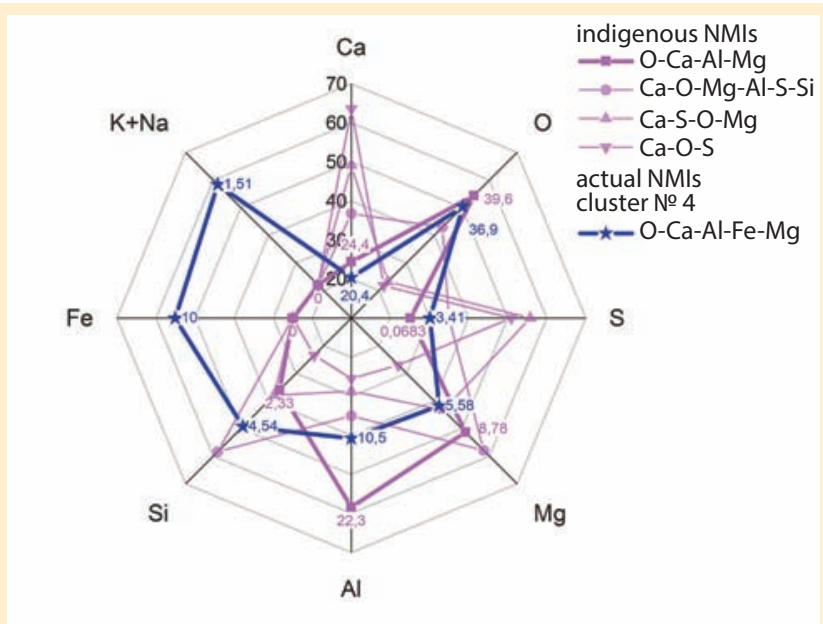

a)

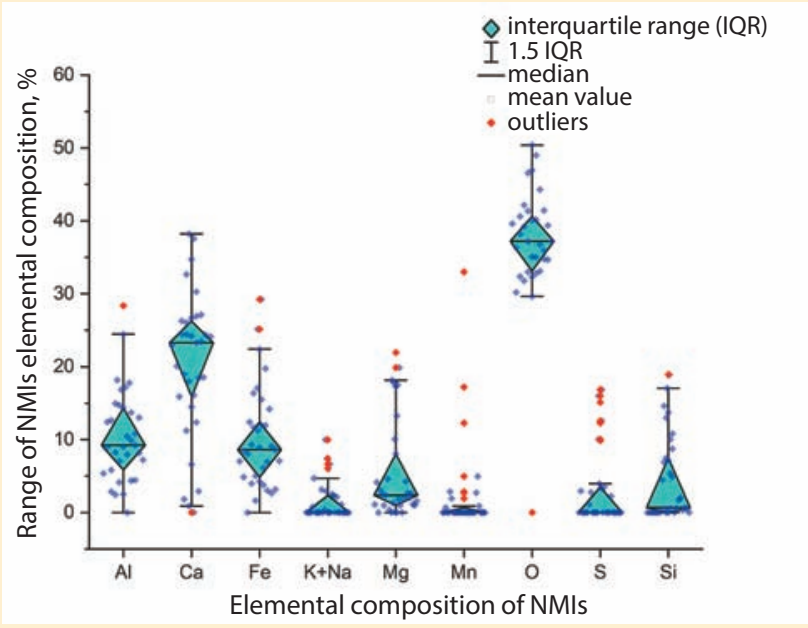

b)

Fig. 7. Compositions of actual inclusions cluster No. 4 and indigenous NMIs in steel (a); compositions of all studied actual inclusions of cluster No. 4 and their descriptive statistics (b)

aluminates and less often with calcium sulfides) with admixtures of exogenous inclusions of magnesia spinel are cluster No. 4. Indigenous inclusions from cluster No. 1 are closest in composition to actual inclusions (Fig. 7a). Some defects contain a lot of iron oxides (Fig. 7b), which indicates welding problems and/or the presence of secondary oxidation products of steel in the defect vicinity.

\section{Examples of inclusion conglomerates found in weld metal discontinuities}

Let us give just one example of inclusions found in the vicinity of defects and belonging to each of the four clusters (Table 4, Fig. 8).

From the analysis of the composition (Table 4) and appearance of inclusion conglomerates found in the weld metal (Fig. 8), it follows that they collected in a local area of the liquid melt with the size of several hundred microns. Moreover, the composition of inclusions is often not limited to a single cluster. In actual metallurgical technology it is impossible to collect in a local volume of molten steel a conglomerate consisting of such a large number and such different compositions of inclusions.

On that basis, we can formulate the following hypothese of the origin of large single conglomerates of inclusions. Deoxidation and modification products were sorbed on the surfaces of refractories, contacting with the molten steel during its ladle treatment and pouring. These mainly primary inclusions, accumulated on the surface of refractories, are out washed by the advancing flow of the melt into the crystallizer during steel pouring. Part of such conglomerates gets into the crystallizer after interaction with slag in the tundish or in the crystallizer, as evidenced by the alkaline earth met- als particles found in their composition. Most of clusters have mixed exo- and indigenous origin, as their composition in different combinations includes particles of refractory oxides, and/or products of secondary oxidation, and/or products of interaction with slag in the tundish or in the crystallizer, as well as indigenous inclusions of deoxidation and modification products.

\section{Implementation of the technique as the plug-in of Thixomet PRO image analyzer}

The interpretation technique of the composition of non-metallic inclusions found in metal products developed in the present investigation is an integral part of the Thixomet PRO image analyzer plug-in, that provides, based
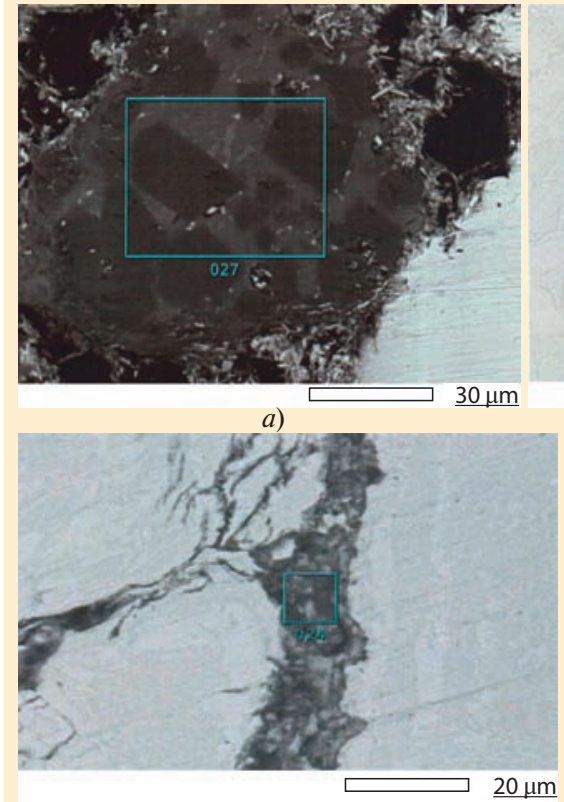

c)
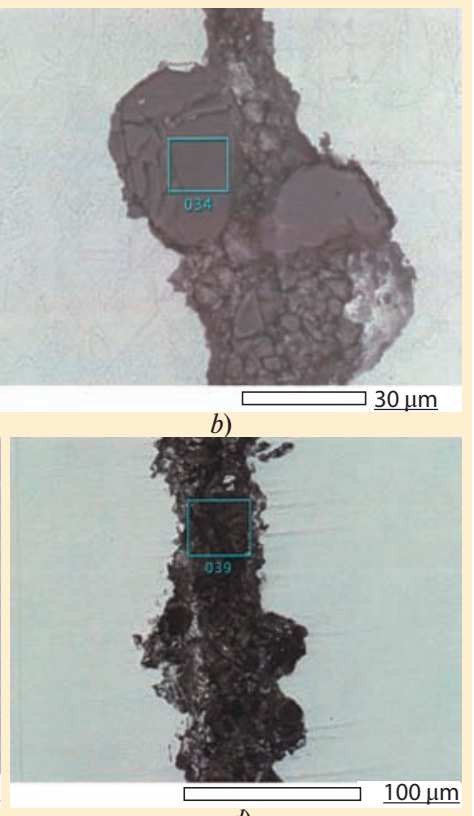

d)
Fig. 8. Conglomerates of inclusions found in discontinuities of weld metal and belonging to clusters (Table 4): No. 1 (a), No. 2 (b), No. 3 (c), No. 4 (d) 
Table 4. Examples of inclusion conglomerates found in welded joints

\begin{tabular}{|c|c|c|c|c|c|}
\hline \multirow{2}{*}{ Clusters } & \multicolumn{5}{|c|}{ Composition of non-metallic inclusions in the conglome- } \\
& \multicolumn{5}{|c|}{ rates, \% } \\
\cline { 2 - 5 } & $\mathrm{Al}$ & $\mathrm{Ca}$ & $\mathrm{Fe}$ & $\mathrm{Mg}$ & 0 \\
\hline 1 & 34.2 & 12.5 & 0 & 11.5 & \\
\hline 2 & 0 & 0 & 0 & 57.6 & \multirow{2}{*}{ balance } \\
\hline 3 & 14.4 & 2.2 & 46.9 & 6.8 & \\
\hline 4 & 27.1 & 4.97 & 17.5 & 12.2 & \\
\hline
\end{tabular}

on the analysis of external and microstructural features in accordance with GOST 21014-88 [15], to classify surface defects as defects of steelmaking origin due to the quality of a continuous cast billet or as defects of rolling origin, formed during the deformation process. Each such defect has its own unique set of external and microstructural features, so the user definitely classifies it by selecting these features in the Thixomet PRO interface.

In factory practice, when generating a metallographic report by the specialized Thixomet Pro plug-in for an inclusion found in weld metal discontinuities, the cluster of actual NMIs that is closest to the composition of this inclusion will be automatically selected, and its above-mentioned description will be used in the corresponding section of the report.

\section{Summary}

1. Using an example of the quality assessment of welded pipe joints made of J55 API 5L (22GYu) steel, the method of processing the results of factory experts' reports has been developed to interpret the origin of non-metallic inclusions (NMIs) detected in the defects of a welded joints.

2. To estimate the possible indigenous origin of these inclusions, thermodynamic calculations were performed. The results of these calculations are summarized in the form of radar diagrams of four clusters uniting similar composition of deoxidation and modification products. According to the same method, more than a hundred compositions of actual inclusions found in the vicinity of dozens of welded joints and causing the formation of defects were combined into four clusters.

3 . From the joint analysis of the compositions of actual NMIs found in the defects during factory examination and possible compositions of indigenous NMIs as deoxidation and modification products, it follows that none of the four clusters of actual NMIs compositions can be the products of steel deoxidation and modification, at least in pure form.

4. The composition of any of the clusters of indigenous NMIs is not similar to the composition of the first three clusters of actual NMIs compositions found in the vicinity of the defects. Therefore, all these inclusions are definitely of predominantly exogenous origin. The first and second clusters are based on refractory materials of magnesia spinel and magnesium oxide, respectively. The third cluster is based on iron oxide.

5. The fourth cluster consists mainly of liquid deoxidation and modification products similar to the indigenous inclusions of cluster No. 1, which are sorbed on the surface of refractories in contact with the molten steel.
6. Sintered conglomerates of inclusions and refractory particles of the first two and fourth clusters were out washed by the flow of steel melt into the crystallizer during steel pouring. The reasons for the formation of the third cluster are related to "cold welding".

7. The technique is implemented as a plug-in of image analyzer Thixomet PRO and allows to automate the process of generation of expertise conclusions, as well as to accumulate all the information in the database for its subsequent automated processing and analysis.

\section{REFERENCES}

1. Kazakov A. A., Kovalev P. V., Ryaboshuk S. V. Metallurgical examination as the base for determination of origin of defects in metal products. CIS Iron and Steel Review. 2007. Vol. 2. pp. 7-13.

2. Kazakov A. A., Kovalev P. V., Chigintsev L. S. et. al. The nature of defects of hot-rolled sheet steel pipe grades. Part 1. Defects having a steelmaking nature. Chernye Metally. 2007. No. 11. pp. 8-15.

3. Kazakov A. A., Kovalev P. V., Andreeva S. V. et. al. The nature of defects of hot-rolled sheet steel pipe grades. Part 2. Defects formed at the stage of rolling production. Chernye Metally. 2008. No. 12. pp. 10-14.

4. Kazakov A. Nonmetallic inclusions in steel - origin, estimation, interpretation and control. Microscopy and Microanalysis. 2016. Vol. 22. pp. 1938-1939. DOI: 10.1017/ S1431927616010539.

5. In-Ho Jung I., Decterov S., Pelton A. Computer applications of thermodynamic databases to inclusion engineering. ISIJ International. 2004. Vol. 44. Iss. 3. pp. 527-536. DOI: 10.2355/ isijinternational.44.527.

6. Adaba O., Kaushik P., O’Malley R., Lekakh S. et al. Characteristics of spinel inclusions formed after reoxidation of calciumtreated aluminum-killed steel. Proceedings of the Iron and Steel Technology Conference. 2016. Vol. 3. pp. 2559-2572.

7. Andersson J.-O., Helander T., Höglund L., Shi P., Sundman B. Thermo-Calc and DICTRA, computational tools for materials science. Calphad. 2002. Vol. 26. Iss. 2. pp. 273-312. DOI: 10.1016/S0364-5916(02)00037-8.

8. BaleC.W., Bélisle E., Chartrand P., Decterov S.A., Eriksson G. etal. FactSage thermochemical software and databases - 2010-2016. Calphad. 2016. Vol. 54. pp. 35-53.

9. Jung I. Overview of the applications of thermodynamic databases to steelmaking processes. Calphad. 2010. Vol. 34. Iss. 3. pp. 332-362. DOI: 10.1016/j.calphad.2010.06.003.

10. Li Y., Yang W., Zhang L. Formation mechanism of MgO containing inclusions in the molten steel refined in $\mathrm{MgO}$ refractory crucibles. Metals. 2020. Vol. 10. p. 444. DOI: 10.3390/met10040444.

11. Chunyang Liu, Xu Gao, Sun-joong Kim, Shigeru Ueda, Shinya Kitamura, Dissolution Behavior of $\mathrm{Mg}$ from $\mathrm{MgO}-\mathrm{C} \mathrm{Re}$ fractory in Al-killed Molten Steel. ISIJ International. 2018. Vol. 58. Iss. 3, pp. 488-495. DOI: 10.2355/ isijinternational. ISIJINT-2017-593

12. Kazakov A. A., Zhitenev A. I., Salynova M. A. Extension of ASTM E2283 standard practice for the assessment of large exogenous nonmetallic inclusions in super duty steels. CIS Iron and Steel Review. 2019. Vol. 18. pp. 20-26. DOI: $10.17580 / \mathrm{ci}-$ sisr.2019.02.01

13. Kazakov A. A., Murysev V. A., Kiselev D. V. Interpretation of nature of non-metallic inclusions in assessing the quality of metal products in the industrial conditions. Chernye Metally. 2021. No. 9. pp. 47-54. DOI: 10.17580/chm.2021.09.08

14. Jain A. K., Murty M. N., Flynn P. J. Data clustering: A ACM Computing Surveys. 1999. Vol. 31. No. 3. pp. 1-69. DOI: $10.1145 / 331499.331504$.

15. GOST 21014-88. Rolled products from ferrous metals. Surface defects. Terms and definitions. Introduced: 01.01.1990. Moscow: Izdatelstvo standartov. 1988. 